CLINICAL STUDY

\title{
Polymorphisms of the drug transporter gene $A B C B 1$ predict side effects of treatment with cabergoline in patients with PRL adenomas
}

\author{
A P Athanasoulia ${ }^{1}$, C Sievers ${ }^{1}$, M Ising $^{2}$, A C Brockhaus ${ }^{3}$, A Yassouridis ${ }^{3}$, G K Stalla ${ }^{1}$ and M Uhr ${ }^{4}$ \\ Departments of ${ }^{1}$ Internal Medicine, Endocrinology and Clinical Chemistry and ${ }^{2}$ Molecular Psychology, Max Planck Institute of Psychiatry, \\ Kraepelinstrasse 2-10, 80804 Munich, Germany, ${ }^{3}$ Division of Biostatistics, Kraepelinstrasse 2-10, 80804 Munich, Germany and ${ }^{4}$ Division of \\ Pharmacokinetics and CSF Analysis, Kraepelinstrasse 2-10, 80804 Munich, Germany \\ (Correspondence should be addressed to A P Athanasoulia; Email: athanasoulia@mpipsykl.mpg.de)
}

\begin{abstract}
Introduction: Treatment with dopamine agonists in patients with prolactin (PRL) adenomas and Parkinson's disease is associated with central side effects. Central side effects may depend on a substance's ability to pass the blood-brain barrier, which can be actively controlled by transporter molecules such as the P-glycoprotein (P-gp) encoded by the ABCB1 gene.

Materials and methods: We aimed to determine whether cabergoline is transported by the P-gp and whether polymorphisms of its encoding $A B C B 1$ gene predict central side effects of cabergoline therapy in patients with PRL adenomas. i) In an experimental mouse model lacking the homologues of the human $A B C B 1$ gene ( $A b c b 1 a b$ double knockout mouse model), we examined whether cabergoline is a substrate of the P-gp using eight mutant and eight wild-type mice. ii) In a human case-control study including 79 patients with PRL adenomas treated with cabergoline at the Max Planck Institute of Psychiatry in Munich, we investigated the association of four selected ABCB1 gene single nucleotide polymorphisms (SNPs) (rs1045642, rs2032582, rs2032583 and rs2235015), with the occurrence of central side effects under cabergoline therapy.

Results: i) In the experimental mouse model, we observed that brain concentrations of cabergoline were tenfold higher in the mutant mice compared with their wild-type littermates, implying that cabergoline is indeed a substrate of the transporter P-gp at the blood-brain barrier level. ii) In the human study, we observed significant negative associations under cabergoline for the C-carriers and heterozygous CT individuals of SNP rs1045642 with two central side effects (frequency of fatigue and sleep disorders) and for the G-carriers of SNP rs2032582 with the enhancement of dizziness. For the SNPs rs2235015 and rs2032583, no associations with central side effects under cabergoline were found. Discussion: This is the first study demonstrating that individual $A B C B 1$ gene polymorphisms, reflecting a different expression and function of the P-gp, could predict the occurrence of central side effects under cabergoline. Our findings can be viewed as a step into personalised therapy in PRL adenoma patients.
\end{abstract}

European Journal of Endocrinology 167 327-335

\section{Introduction}

Prolactin (PRL) hypersecretion is the most common endocrine abnormality due to hypothalamic-pituitary disorders, and PRL adenomas, adenomas arising from lactotroph cells of the anterior pituitary, account for about $40 \%$ of all pituitary tumours with an annual incidence of six to ten cases per million population (1). The primary therapy option is the dopamine agonist therapy with cabergoline, a selective ergoline derivative dopamine agonist of dopamine 2 (D2) receptors (2). The most common side effects under cabergoline therapy include not only gastrointestinal symptoms but also postural hypotension, dizziness and headaches, with a varying frequency in different study populations (12-31\% for nausea, $12-30 \%$ for headaches, $6-25 \%$ for dizziness, $13 \%$ for fatigue and $10-15 \%$ for abdominal symptoms) $(3,4)$, symptoms that lead in some cases to discontinuation of cabergoline. In patients with Parkinson's disease, where the symptoms of the loss of dopaminergic neurons are being treated with cabergoline and other dopamine agonists, similar data for nausea, dizziness, headaches and fatigue have been documented $(5,6,7)$. Apart from these common side 
effects, some other, rarer central side effects such as impulse control disorders (ICDs) (i.e. pathological gambling, compulsive shopping, hypersexuality and binge eating) have been recently reported $(8,9,10,11)$. These symptoms are generally characterised by the maladaptive nature of the preoccupations and the inability to control these urges. They mainly have a de novo onset after the initiation of dopamine therapy in higher dosages, usually seen in patients with Parkinson's disease (12). Problems related to pathological gambling have been described in Parkinson patients with a varying frequency from 3.4 up to $6.1 \%$ (13), and significantly increase beyond that of the general population. In nearly all described cases, patients had no history of gambling before dopamine agonist therapy $(14,15)$. Recent data from a multicentre study on 3090 patients with Parkinson's disease in the USA further support these findings, reporting an incidence of all ICDs as high as $13.6 \%$ (16). Symptoms such as pathological gambling, compulsive shopping and hypersexuality tendency have also been described in patients with restless legs syndrome treated with dopamine agonists, but the prevalence is less clearly established $(17,18)$. Regarding sleep disorders, add-on cabergoline therapy has been reported to improve sleep quality in advanced Parkinson's disease patients (19, 20), but in de novo patients with Parkinson's disease, it may have negative effects on rapid eye movement (REM) sleep (21), and studies on PRL adenoma patients have not been conducted up to now.

In patients with PRL adenomas, these rare central side effects have not systematically been investigated, whereas distinct dopaminergic personality patterns have been already described (22). Until now, there is only one case series and three case reports that describe dopamine agonist-induced pathological gambling and hypersexuality $(8,9,10,11)$. All patients had a free psychiatric history and developed the symptoms after initiation of the low-dose dopamine agonist treatment.

The central side effects of systematically administered drugs, such as cabergoline, may depend on their ability to pass the blood-brain barrier, the physical barrier of the $\mathrm{CN}$ formed by endothelial cells and astrocytic expansions that restrict the penetration of specific molecules into the brain. The concentration of the medication in the $\mathrm{CN}$ has been found to be actively controlled by transporter molecules that are expressed at the luminal membrane of the endothelial cell lining. One of these molecules that transports substrates out of cells back into the blood circulation is a P-glycoprotein (P-gp), encoded by the $A B C B 1$ gene (or alternatively multidrug resistance gene - MDR 1), located on chromosome 7 (23). P-gp acts as an efflux transporter that uses ATP as an energy source, in order to transport certain substances out of the brain, and probably developed as a protective mechanism for the $\mathrm{CN}$ against harmful substances (23). If the function and expression of P-gp is reduced, the amount of a substrate that is removed from the brain tissue is reduced, and the intracerebral concentration remains high. On the contrary, by inducing the function of P-gp, larger amounts of the substrate are excreted, keeping the brain drug concentration low. If patients are treated with a substrate of P-gp, functionally relevant genetic variants in the $A B C B 1$ transporter gene could influence intracerebral drug concentrations and, thereby, clinical response and side effect profile $(23,24)$.

Genetic variants in the $A B C B 1$ transporter P-gp correlate with different functional levels of the P-gp and intracerebral concentrations of antidepressants. This is associated with a different clinical response to these antidepressants $(23,24,25)$. To date, more than 95 single nucleotide polymorphisms (SNPs) have been identified (23). The following four SNPs: rs045642, rs2032582, rs2032583 and rs2235015, have been associated with an altered expression and function of the P-gp.

In a recent study of Uhr et al. (24), there was a clear difference in the genotype distribution of rs2032583 and rs2235015 between remitters and non-remitters to antidepressant therapy in favour of $\mathrm{C}$ - and T-carriers respectively. Another study by Kato et al. (26) showed that the C-variant of rs1045642 and the G-variant of rs2032582 were similarly linked to a higher expression and function of P-gp, resulting in a poorer treatment response and lower remission rates to antidepressants. We therefore hypothesised that the $\mathrm{C}$ - and T-carriers of SNPs rs2032583 and rs2235015, linked to decreased function and activity of P-gp, could be a riskaggravating factor for the occurrence of side effects under cabergoline. On the contrary, the C-variant of rs1045642 and the G-variant of rs2032582 were found to lead to increased functionality of P-gp and therefore could be a protective factor for the occurrence of side effects. We therefore selected these four SNPs for genotyping analyses in our study.

The aim of our project was to determine whether the functionality of P-gp is related to cabergoline levels in the brain by means of in vivo experiments with an Abcb1ab double knockout mouse model. Among all dopamine agonists used for the treatment of PRL adenomas, we chose cabergoline as it is the gold standard medical treatment for PRL adenoma patients (2). We further planned to investigate whether polymorphisms in the $A B C B 1$ gene could predict the occurrence of central side effects in PRL adenoma patients treated with cabergoline.

\section{Materials and methods}

\section{In vivo experiments using Abcb1a and Abcb1b double knockout mice}

To examine whether cabergoline is a substrate of P-gp, we developed an in vivo assay using mouse mutants 
lacking the homologues of the human $A B C B 1$ gene (i.e. Abcb1ab double knockout mice) and used eight wild-type and eight Abcb1ab double knockout mice. All animal experiments were conducted in accordance with the Guide for the Care and Use of Laboratory Animals of the Government of Bavaria, Germany, as described extensively in a previous study (24). We only used male mice in order to avoid any hormonal implications in our experiments. In our experimental model, cabergoline was administered subcutaneously in the nape of the neck through surgically implanted osmotic infusion pumps, which continuously delivered cabergoline at the scheduled concentration of $3 \mu \mathrm{g}$ daily for a period of 11 days. After this period, the mice were anaesthetised and killed. The dissected organs (brain, spleen, kidneys, lungs, liver, testes and intestine) were homogenised, a liquid-liquid extraction procedure was performed and HPLC measurements and statistics were carried out, as described previously (24), in order to assess the organ/blood ratio in both the $A b c b 1 a b^{(-/-)}$mutant mice and their wild-type littermates.

\section{Human case-control SNP association study}

Patients diagnosed with PRL adenomas were identified through the electronic database of our Institute and contacted by letter and/or during their regular visits. Written informed consent was obtained from all the participants in the study, and the study was approved by the ethics committee of the Ludwig-MaximilianUniversity of Munich. Patients over 18 years with the diagnosis of a PRL adenoma (micro- or macroadenomas) treated with cabergoline during the disease history were included in the study. Exclusion criteria were age under 18 years, patients unwilling to participate and hyperprolactinaemia due to other causes (e.g. medical treatment, hypothalamic disease, other pituitary disease, pregnancy and lactation). Patients that experienced the examined symptoms (or side effects) under cabergoline treatment (answered with 'yes') were considered as cases and patients that did not experience these symptoms (answered with 'no' for the relevant question) as control group. The exact numbers in the case and control groups depended on the symptom and is presented in detail in Table 1 (e.g. in the case of headaches under cabergoline, the number of cases was 26 and there were 38 controls who did not experience this symptom. In the case of enhancement of headaches under cabergoline, the cases were ten patients and the controls 55).

\section{Questionnaires}

The patients' central side effects were investigated with standardised and customised questionnaires that were sent to these patients with the request to return them in prepaid envelopes. The questionnaire encompassed socioeconomic and baseline characteristics and questions regarding their medical history. Clinical characteristics of the subjects were collected with regard to disease history, tumour characteristics, previous and present therapy and comorbidities, as well as present complaints, as published previously (27). We asked the patients to evaluate their symptoms in terms of presence, change, enhancement, reduction or consistency under dopamine agonist therapy. In the case of missing data or uncertainty, additional information was obtained by review of patient files. The first draft of the questionnaire was developed by identifying areas of interest, and after screening and research on potential standardised questionnaires. The first version of the questionnaire was distributed to: i) a group of five experts at the Max Planck Institute; and ii) a small

Table 1 Central side effects under cabergoline treatment.

\begin{tabular}{|c|c|c|c|c|c|c|c|}
\hline & \multirow{2}{*}{\multicolumn{2}{|c|}{$\begin{array}{l}\text { Presence of symptom } \\
\text { under cabergoline }\end{array}$}} & \multicolumn{5}{|c|}{ Change of symptom under cabergoline } \\
\hline & & & \multicolumn{2}{|c|}{ Enhancement } & \multicolumn{3}{|c|}{ Reduction or consistency } \\
\hline & $n$ & $\%^{a}$ & $n$ & $\%$ & $n$ & $\%$ & $P$ value $^{\mathrm{b}}$ \\
\hline Fatigue & $35(65)^{c}$ & 53.8 & 16 & 24.2 & 50 & 75.8 & $<0.001$ \\
\hline Headaches & $26(64)$ & 40.6 & 10 & 15.4 & 55 & 84.6 & 0.001 \\
\hline Dizziness & $22(64)$ & 34.4 & 7 & 10.9 & 57 & 89.1 & $<0.001$ \\
\hline Decreased libido & $18(66)$ & 27.3 & 6 & 9.2 & 59 & 90.8 & $<0.001$ \\
\hline Increased libido & $16(65)$ & 24.6 & 16 & 25.8 & 46 & 74.2 & $<0.001$ \\
\hline Depressed mood & $26(65)$ & 40 & 12 & 18.2 & 54 & 81.8 & $<0.001$ \\
\hline Aggressiveness & $17(65)$ & 26.2 & 7 & 10.6 & 59 & 89.4 & $<0.001$ \\
\hline Anxiety & $19(64)$ & 29.7 & 7 & 10.9 & 57 & 89.1 & $<0.001$ \\
\hline Visual hallucinations & $2(65)$ & 3.1 & 1 & 1.5 & 64 & 98.5 & 0.031 \\
\hline Gambling & $1(65)$ & 1.5 & 1 & 1.5 & 64 & 98.5 & 0.015 \\
\hline
\end{tabular}

${ }^{\text {a }}$ Percentage of cases in the group of patients that answered the question.

${ }^{b} \chi^{2}$ between presence and change of symptom under cabergoline (enhancement or reduction and consistency of symptom).

cThe total number of patients that answered the question is given in parenthesis (cases and controls). 
group of patients of the Endocrine Outpatient Unit of the Max Planck Institute of Psychiatry, for improvements and revision. The final questionnaire (Supplementary Data, see section on supplementary data given at the end of this article) was evaluated by the Department of Epidemiological Psychology of the Max Planck Institute of Psychiatry and was sent to the patients in May 2009. A database was created with Microsoft Access (Windows 2000), where all data were transferred for statistical analyses in Statistical Package for the Social Sciences (SPSS IBM Inc., New York, NY, USA).

\section{DNA preparation, SNP selection and genotyping of the ABCB1 gene}

In order to perform the genetic analyses, we collected blood or saliva samples (if it was the patients' preference) to determine the potential associations between the $A B C B 1$ gene variants and central side effects of cabergoline treatment in these patients. Forty milliliters of EDTA blood were drawn from each patient and DNA was extracted from fresh blood using the Puregene whole-blood DNA extraction kit (Gentra Systems, Minneapolis, MN, USA). Alternatively, for the patients that did not attend our Outpatient Unit at the study point, Oragene DNA self-collection kits (OG-500tube or OG-250-disc format) were sent to their home address, and they were asked to return them with saliva samples in prepaid envelopes. Saliva samples were collected according to the manufacturer's instructions that were enclosed in the German language. A $500 \mu \mathrm{l}$ aliquot of an Oragene DNA saliva sample was used for the DNA extraction according to the manufacturer's instructions. Genotyping was performed with a LightCycler 480 Genotyping Master (detailed genotyping procedure presented in Supplementary Materials and methods, see section on supplementary data given at the end of this article). Four $A B C B 1$ SNPs were genotyped (Table 2), SNPs were selected from dbSNP (http://www.ncbi.nlm.nih.gov:80/) according to previously published data, that revealed altered expression and function of the P-gp. None of the SNPs showed a significant deviation from the HardyWeinberg equilibrium and all genotypes could be determined (call rate 100\%).

\section{Statistical analysis}

Statistical analysis was performed using the SPSS Version 16 for Windows. In the frame of the formulated hypothesis of the central side effects of treatment with cabergoline, percentages and frequencies of these symptoms under hormonal treatment were calculated. We also retrieved data from the disease and personal history and medical procedures, and means and s.D. were calculated.

The differences in continuous and categorical variables between two groups were analysed by the unpaired $t$-test (two tailed) and $\chi^{2}$. A two-tailed $P$ value of 0.05 was considered statistically significant with a 95\% confidence interval after corrections for multiple tests were performed. Empirical, instead of asymptotic, $P$ values were reported. These were calculated with a permutation-based method using permutations. SNPs were analysed using WG-permer software (http://www.wg-permer.org) by testing for the following models of association: allelic, carrier and heterozygote vs homozygote. Correction for multiple tests was performed using the minimum $\mathrm{P}$ method of Westfall \& Young (28) (Pwycor).

\section{Results}

\section{In vivo experiments using Abcb1a and Abcb1b double knockout mice}

As P-gp transfers its substrate against a concentration gradient outside of the brain back into the blood circulation, animals lacking P-gp should have higher substance concentrations in the brain than control animals. This is exactly what we observed in our in vivo experiments. As shown in Fig. 1, brain concentrations of cabergoline were ten times higher in the mutant mice compared with their wild-type littermates (data represented as an organ/plasma concentration ratio). In addition, differences in the testes/plasma ratios were found for cabergoline, which indirectly indicate that the blood-testis barrier is also partially regulated by P-pg. No differences in the organ/plasma ratio concentration of cabergoline were found between $A b c b 1 a b^{(-1-)}$ mutants and their wild-type littermates for other organs such as the spleen, kidney, liver, lungs and intestine (Fig. 1).

Table 2 Information on genotyped SNPs of $A B C B 1$ gene. Chromosomal positions are given according to the February 2009 (hg19) human reference sequence database of the International Human Genome Sequencing Consortium.

\begin{tabular}{|c|c|c|c|c|c|c|c|}
\hline SNP & $\begin{array}{l}\text { Chromosomal } \\
\text { position }\end{array}$ & $\begin{array}{l}\text { Genomic } \\
\text { localisation }\end{array}$ & Map-pos & Alleles & HWE & MAF & Call rate \\
\hline \multicolumn{8}{|l|}{$A B C B 1$} \\
\hline rs1045642 & 7 & Exon 26 & 87138645 & $\mathrm{C} / \mathrm{T}$ & 0.65 & 0.44 & 1.00 \\
\hline rs2032582 & 7 & Exon 21 & 87160618 & $\mathrm{G} / \mathrm{T}$ & 1.00 & 0.47 & 1.00 \\
\hline rs2032583 & 7 & Intron 21 & 87160561 & $\mathrm{C} / \mathrm{T}$ & 0.68 & 0.16 & 1.00 \\
\hline rs2235015 & 7 & Intron 4 & 87199564 & $\mathrm{G} / \mathrm{T}$ & 0.49 & 0.20 & 1.00 \\
\hline
\end{tabular}

HWE, $P$ values of the Hardy-Weinberg equilibrium test; MAF, minor allele frequency. 


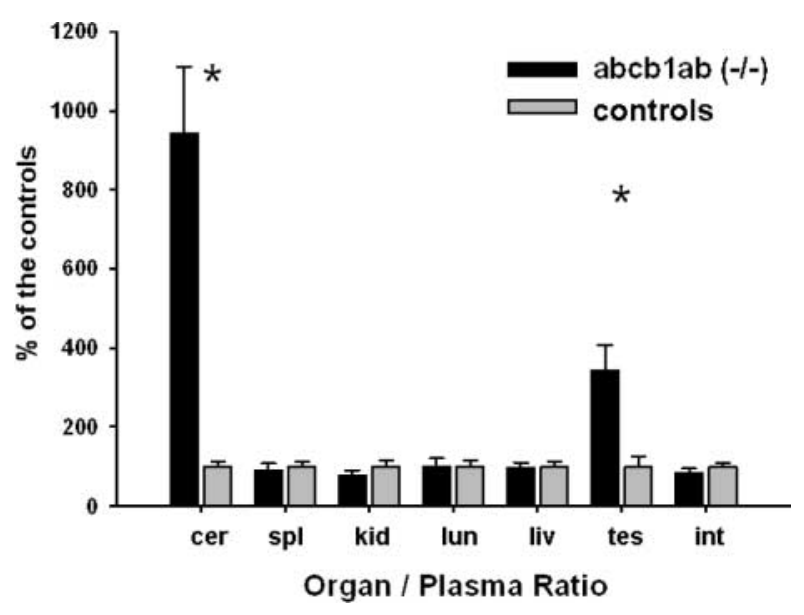

Figure 1 Blood-organ barrier function for cabergoline. Organ/ plasma ratio of cabergoline concentration in $A b c b 1 a b^{(-1-)}$ mice compared with wild-type controls after s.c. administration of cabergoline for 11 days via osmotic pumps. The organ/plasma ratios are shown as percentage of the control. *Statistical significance between the knockout mutants and controls $(P<0.05)$. cer, cerebrum; spl, spleen; kid, kidney; lun, lung; liv, liver; tes, testes; int, intestine. Values are shown as mean \pm S.E.M.

\section{Human case-control SNP association study}

From the initial group of 92 patients treated at the Endocrine Outpatient Unit of the Max Planck Institute of Psychiatry that were enrolled during a period of 2 years between December 2008 and January 2011, only the cabergoline group was selected for further analysis provided below $(n=79: 17$ males and 62 females, mean age at study time $51.5 \pm 13.6$ years, mean body mass index $25.7 \pm 7.2 \mathrm{~kg} / \mathrm{m}^{2}$, mean maximum dose of cabergoline $1 \mathrm{mg} /$ week, range $0.25-7 \mathrm{mg}$ ).

The initial diagnosis was equal to micro- $(54.4 \%)$ and macroadenomas (44.3\%). The mean serum PRL concentration at baseline was $982.3 \pm 2245.3 \mathrm{ng} / \mathrm{ml}$. Eight patients had undergone surgery (six transsphenoidal and two transcranial) and one of these patients had received additional radiotherapy. In all patients, pituitary function (with not only basal fasting measurements of PRL, IGF1, TSH, free thyroxine, free triiodothyronine, LH, FSH, testosterone and oestradiol but also stimulation tests such as short ACTH test, GHRH/arginine test or insulin hypoglycaemia test) was assessed. At the study point, 54 patients had normalised PRL values. Fifteen patients had the diagnosis of pituitary insufficiency of at least one axis that was, not surprisingly, strongly correlated with the diagnosis of a macroadenoma $(P<0.001)$. The most affected axis was the gonadotropic axis with $12.7 \%$, followed by the corticotropic $(8.9 \%)$, the somatotropic $(5.1 \%)$ and the thyrotropic axes $(3.8 \%)$. The diagnosis of pituitary deficiency was based on previously reported criteria (29). All patients were studied under optimised hormone replacement.
In the study population of 79 patients with PRL adenomas treated with cabergoline, mainly central side effects/symptoms such as headaches, increased libido, depressed mood, sleep disorders, fatigue, dizziness and aggressiveness were reported under cabergoline therapy (Table 1).

We evaluated all the symptoms in terms of presence and change (enhancement vs reduction or consistency). The patients reported primarily the enhancement of fatigue and increased libido and secondarily the enhancement of depressed mood. In terms of all disorders examined, we found statistically significant changes of all symptoms when compared with the presence of the symptoms under treatment. All the symptoms addressed and the frequencies observed in terms of presence and change under treatment with cabergoline are presented in Table 1 .

\section{Association analysis among the seven most common neuropsychiatric central side effects of cabergoline and $A B C B 1$ polymorphisms in PRL adenoma patients treated with cabergoline}

As cabergoline was the only dopamine agonist tested to be a substrate of P-gp, we examined the effects of the $A B C B 1$ SNPs on self-reported central side effects under treatment with cabergoline only. We selected the most common central side effects (fatigue, headaches, sleep disorders, dizziness, increased libido, depressed mood and aggressiveness) and tested them in different genetic models. In the carrier model, the carrier of a specific nucleotide was compared with the non-carrier. In the allelic model, each nucleotide was evaluated having a twofold higher effect in the genotype, whereas in the heterozygous vs homozygous genotype model, each SNP was compared.

\section{Association of SNPs rs1045642, rs2032582, rs2032583 and rs2235015 with central side effects under cabergoline treatment}

We found that the SNP rs1045642 had an influence on two side effects under cabergoline: fatigue and sleep disorders (Supplementary Table 1, see section on supplementary data given at the end of this article and Table 3). More specifically, significant effects were observed for the C-carriers of rs1045642 that presented less frequent fatigue under cabergoline in comparison with non-C-carriers (Pwycor $=0.04, \quad \mathrm{OR}=0.23)$. Additionally, the heterozygous CT individuals presented less frequent sleep disorders in comparison with homozygous CC or TT (Pwycor $=0.02, \mathrm{OR}=0.20)$.

SNP rs2032582 turned out to have an influence only on enhancement of dizziness under cabergoline in favour of G-carriers (Supplementary Table 2, see section on supplementary data given at the end of this article and Table 4). More specifically, in the analysis of 
Table 3 Significant associations of SNP rs1045642 with side effects under cabergoline treatment.

\begin{tabular}{|c|c|c|c|c|c|c|}
\hline & \multicolumn{3}{|c|}{ Presence of symptom } & \multicolumn{3}{|c|}{ Enhancement of symptom } \\
\hline & Pnom & Pwycor $^{a}$ & OR & Pnom & Pwycor $^{a}$ & OR \\
\hline \multicolumn{7}{|l|}{ Headaches } \\
\hline Carrier-C & 0.49 & 0.90 & 1.49 & 0.12 & 0.39 & 0.34 \\
\hline Carrier-T & 0.73 & 0.99 & 0.78 & 1.00 & 1.00 & 0.99 \\
\hline Het./Hom. & 0.73 & 0.99 & 1.21 & 0.17 & 0.44 & 0.31 \\
\hline Allelic & 0.50 & 0.86 & 1.31 & 0.34 & 0.68 & 0.59 \\
\hline \multicolumn{7}{|c|}{ Sleep disorders } \\
\hline Carrier-C & 0.07 & 0.20 & 0.36 & 0.36 & 0.80 & 0.51 \\
\hline Carrier-T & 0.24 & 0.63 & 0.46 & 0.24 & 0.56 & 0.41 \\
\hline Het./Hom. & 0.01 & 0.02 & 0.20 & 0.05 & 0.16 & 0.21 \\
\hline Allelic & 0.65 & 0.96 & 0.83 & 0.96 & 1.00 & 1.03 \\
\hline \multicolumn{7}{|l|}{ Fatigue } \\
\hline Carrier-C & 0.02 & 0.04 & 0.23 & 0.57 & 0.96 & 0.68 \\
\hline Carrier-T & 0.63 & 0.99 & 1.39 & 0.60 & 0.99 & 0.69 \\
\hline Het./Hom. & 0.07 & 0.22 & 0.36 & 0.30 & 0.70 & 0.52 \\
\hline Allelic & 0.06 & 0.15 & 0.48 & 0.90 & 1.00 & 0.96 \\
\hline \multicolumn{7}{|l|}{ Dizziness } \\
\hline Carrier-C & 0.43 & 0.86 & 0.61 & 0.02 & 0.10 & 0.15 \\
\hline Carrier-T & 0.74 & 0.99 & 0.80 & 0.60 & 0.90 & 1.85 \\
\hline Het./Hom. & 0.31 & 0.71 & 0.54 & 0.10 & 0.30 & 0.17 \\
\hline Allelic & 0.75 & 0.99 & 0.87 & 0.08 & 0.19 & 0.29 \\
\hline
\end{tabular}

Statistically significant effects are marked in bold - genotypes $C C=18, C T=33, T T=21$ and missing $=7$.

${ }^{a}$ Corrected for the number of SNPs tested according to the Westfall \& Young method.

SNP rs2032582, G-carriers seemed to be protected from enhancement of dizziness under cabergoline when compared with non-G-carriers (Pwycor $=0.05$, $\mathrm{OR}=0.14$ ). For SNPs rs2032583 and rs2235015, our study showed no statistically significant influence on the examined side effects.

\section{Discussion}

For the first time, we could demonstrate that cabergoline is a substrate of the transporter molecule P-gp at the level of the blood-brain barrier in an experimental mouse model. Going a step further, we showed that this fact has consequences for cabergoline-treated humans, insofar that genetic variants of the $A B C B 1$ gene, which encodes the P-gp, account for differences in the central side effects of cabergoline, most likely by influencing its concentration in the brain.

The P-pg activity depends on the expression of the molecule and, also, on its functionality. Both parameters seem to interfere and secondarily influence intracerebral concentrations of the substrates of P-gp. There are only a few studies to date addressing the influence of the P-gp encoding $A B C B 1$ gene polymorphisms, and all of them refer to antidepressants that are substrates of this molecule (23). In this case, a low P-gp activity is desired in order to achieve higher intracerebral concentrations and to increase the remission rates. The interindividual and genotypic variability of the P-gp in the blood-brain barrier could influence secondarily the degree of expression and the functionality of the $A B C B 1$ gene product and, therefore, directly affect the therapeutic effectiveness of agents that are substrates of P-gp. Mihaljevic Peles et al. (30) implicated that rs203582 and rs1045642 did not influence the response to paroxetine, and both Peters et al. (31) and Laika et al. (32) showed that none of the genetic polymorphisms in the pharmacokinetic genes examined were significantly associated with response or tolerance. However, both Kato et al. (26) and Hoffmeyer et al. (33) reported that the C-variant of SNP rs1045642 and G-variant of SNP rs2032582 were associated with higher P-gp expression and function and, therefore, poor response to antidepressants. On the other hand, conflicting results have also been reported (34), showing an increased remission of depression in the G-carriers of SNP rs2032582 due to higher antidepressant intracerebral concentrations.

These latest results are in accordance with our findings, reporting fewer central side effects under cabergoline in those individuals that have the "protective' genotype. Nevertheless, our study was focused on the evaluation of some specific genetic predictors of the $A B C B 1$ gene. We suppose that there are further transporting molecules and genetic pathways that influence the metabolism and action of cabergoline in the brain circulation, and further studies need to be conducted to elucidate these mechanisms.

At this point, it has to be underlined that the goal of our study was not to examine the effect of the individual $A B C B 1$ gene polymorphisms on treatment response or dose required to achieve remission, as the pituitary gland is located outside of the blood-brain barrier where the P-gp is controlling the penetration of the substrates 
Table 4 Significant association of SNP rs2032582 with side effects under cabergoline treatment.

\begin{tabular}{|c|c|c|c|c|c|c|}
\hline & \multicolumn{3}{|c|}{ Presence of symptom } & \multicolumn{3}{|c|}{ Enhancement of symptom } \\
\hline & Pnom & Pwycor $^{a}$ & OR & Pnom & Pwycor $^{a}$ & OR \\
\hline \multicolumn{7}{|l|}{ Headaches } \\
\hline Carrier-G & 0.86 & 1.00 & 1.16 & 0.08 & 0.27 & 0.27 \\
\hline Carrier-T & 0.39 & 0.79 & 0.60 & 0.37 & 0.68 & 0.49 \\
\hline Het./Hom. & 0.56 & 0.94 & 0.71 & 0.02 & 0.07 & 0.11 \\
\hline Allelic & 0.48 & 0.86 & 1.32 & 0.73 & 0.99 & 0.82 \\
\hline \multicolumn{7}{|c|}{ Sleep disorders } \\
\hline Carrier-G & 0.60 & 0.93 & 0.68 & 0.23 & 0.53 & 0.41 \\
\hline Carrier-T & 0.62 & 0.98 & 0.72 & 0.25 & 0.61 & 0.46 \\
\hline Het./Hom. & 0.33 & 0.74 & 0.58 & 0.04 & 0.12 & 0.20 \\
\hline Allelic & 1.00 & 1.00 & 1.01 & 1.00 & 1.00 & 1.01 \\
\hline \multicolumn{7}{|l|}{ Fatigue } \\
\hline Carrier-G & 0.52 & 0.91 & 0.63 & 0.23 & 0.49 & 0.43 \\
\hline Carrier-T & 0.19 & 0.35 & 2.22 & 0.82 & 1.00 & 0.81 \\
\hline Het./Hom. & 0.50 & 0.91 & 1.42 & 0.21 & 0.55 & 0.44 \\
\hline Allelic & 0.20 & 0.45 & 0.61 & 0.62 & 0.95 & 0.80 \\
\hline \multicolumn{7}{|l|}{ Dizziness } \\
\hline Carrier-G & 1.00 & 1.00 & 1.06 & 0.01 & 0.05 & 0.14 \\
\hline Carrier-T & 0.90 & 1.00 & 1.08 & 0.31 & 0.68 & 3.03 \\
\hline Het./Hom. & 0.87 & 1.00 & 1.11 & 0.35 & 0.66 & 0.38 \\
\hline Allelic & 0.98 & 1.00 & 0.99 & 0.03 & 0.09 & 0.28 \\
\hline
\end{tabular}

Statistically significant effects are marked in bold - genotypes $G G=21, G T=34, T T=15$ and $\operatorname{missing}=9$.

${ }^{a}$ Corrected for the number of SNPs tested according to the Westfall \& Young method.

into the $\mathrm{CN}$. As in the case of every study, our investigation also has limitations and strengths.

We first used a mouse model, and not humans, to test the function of P-gp. In humans, P-gp is encoded by a single gene $(A B C B 1)$ located on chromosome 7 . In mice, there are two gene homologues, the $A b c b 1 a$ and the $A b c b 1 b$ (35). Although $A b c b 1 a$ and $A b c b 1 b$ are not always expressed in the same organs, the overall distribution of these genes in mouse tissue seems to coincide with that of the single $A B C B 1$ in humans, indicating that both mouse gene homologues have a similar function in the mouse and in the human $A B C B 1$ gene (24). Another limitation of our experimental model is that we did not conduct measurements of the organ/plasma ratio of cabergoline in the pituitary and separately in the hypothalamus or other brain areas to determine whether there is a direct correlation with the known side effects.

Regarding the limitations of the clinical study, we might have selected a particular group of patients not reflecting the usual PRL adenoma sample, as we are in Endocrine Outpatient Clinic at a psychiatric institute. Additionally, the participation rate of our study was $30 \%$, which might have introduced an additional selection bias. In the initial group of 308 patients, 198 were diagnosed with microadenomas and 110 with macroadenomas, whereas in our study group we observed an equal prevalence of micro- and macroadenomas, probably reflecting the increased health concern of the latest group of patients. We therefore have to assume that in terms of tumour type, our group did not reflect the initial group of patients treated in the
Endocrine Outpatient Clinic. However, both types of adenomas were sufficiently represented.

As expected, few patients underwent surgical therapy, reflecting the high rate of remission under medical treatment. Eighty-six percent of the patients in the initial group received cabergoline, which is the dopamine agonist therapy of choice (2). As our group included subjects with a long disease history, not only cabergoline but also other dopamine agonists such as bromocriptine, lisuride and quinagolide had been additionally used during the disease history and might have influenced the report of symptomatology. Additionally, due to the relatively low response rate, we have to hypothesise that the patients that finally participated in our study probably were more affected by the pituitary lesions and, thus, due to increased health concerns, dedicated their time to participate in our study.

Another additional source of bias is the 'missing data' that occur from a false response or misunderstanding of the questions (measurement bias). The data collected for the study were obtained mainly from the questionnaire and, in the case of missing data or uncertainty, additional information was obtained by file review. Therefore, the results consisted partly of information based on the patient's own perception. The reported trends, e.g. for depressed mood or aggressiveness, reflected the patient's impression of his symptoms and were not validated or diagnosed by a specialised physician according to the ICD-10 (ICD-10: International Statistical Classification of Diseases and Related Health Problems 10th Revision), which might have led to underreporting of the variable 'central side effects'. 
Further, it should be mentioned that for each SNP examined, only a few of the central side effects under cabergoline showed significant correlation. This phenomenon could be attributed to the fact that cabergoline and dopamine in the $\mathrm{CN}$ do not play the same role for all symptoms or that additional factors that were not examined in this study influenced the occurrence of side effects, leading to non significant associations (e.g. other neurotransmitters apart from dopamine have been found to influence the prevalence of depression and this could be reflected by the negative association between this symptom and the examined SNPs).

In summary, this is the first study that, using mouse mutants lacking the homologues of the human $A B C B 1$ gene (i.e. Abcb1ab double knockout mice), demonstrates that cabergoline is a substrate of P-gp. The results from the human case-control SNP association study, although limited by the relatively small number of patients, suggest that polymorphisms of the $A B C B 1$ gene, accounting for differences in function and expression of P-gp and, therefore, the intracerebral bioavailability of cabergoline, could predispose for fatigue, sleep disorders and dizziness under cabergoline. This is the first study showing that $A B C B 1$ gene polymorphisms could account for the occurrence of central side effects of this systematically administered medication, leading to an individual's central side effect profile. This could lead in the future to an adaptation of the treatment of individual patients.

\section{Supplementary data}

This is linked to the online version of the paper at http://dx.doi.org/10. 1530/EJE-12-0198.

\section{Declaration of interest}

The authors declare that there is no conflict of interest that could be perceived as prejudicing the impartiality of the research reported.

\section{Funding}

This work was supported by a scholarship from Pfizer Pharma GmbH, Karlsruhe, Germany to A P Athanasoulia.

\section{Author contribution statement}

The first two and last two authors contributed equally to this work and share joint first and last authorship respectively.

\section{References}

1 Ezzat S, Asa SL, Couldwell WT, Barr CE, Dodge WE, Vance ML \& McCutcheon IE. The prevalence of pituitary adenomas: a systematic review. Cancer 2004101 613-619. (doi:10.1002/ cncr.20412)

2 Melmed S, Casanueva FF, Hoffman AR, Kleinberg DL, Montori VM, Schlechte JA \& Wass JA. Diagnosis and treatment of hyperprolactinemia: an Endocrine Society clinical practice guideline. Journal of Clinical Endocrinology and Metabolism $201196273-$ 288. (doi:10.1210/jc.2010-1692)

3 Webster J, Piscitelli G, Polli A, Ferrari CI, Ismail I \& Scanlon MF. A comparison of cabergoline and bromocriptine in the treatment of hyperprolactinemic amenorrhea. Cabergoline Comparative Study Group. New England Journal of Medicine 1994331 904-909. (doi:10.1056/NEJM199410063311403)

4 Al-Husaynei AJ, Mahmood IH \& Al-Jubori ZS. Comparison of the effects of cabergoline and bromocriptine in women with hyperprolactinemic amenorrhea. Middle East Fertility Society Journal 200813 33-38.

5 Deuschl G, Vaitkus A, Fox GC, Roscher T, Schremmer D \& Gordin A. Efficacy and tolerability of Entacapone versus Cabergoline in parkinsonian patients suffering from wearing-off. Movement Disorders 200722 1550-1555. (doi:10.1002/mds.21473)

6 Bracco F, Battaglia A, Chouza C, Dupont E, Gershanik O, Marti Masso JF \& Montastruc JL. The long-acting dopamine receptor agonist cabergoline in early Parkinson's disease: final results of a 5-year, double-blind, levodopa-controlled study. CNS Drugs 2004 18 733-746. (doi:10.2165/00023210-200418110-00003)

7 Colao A, di Sarno A, Pivonello R, di Somma C \& Lombardi G. Dopamine receptor agonists for treating prolactinomas. Expert Opinion on Investigational Drugs 200211 787-800. (doi:10.1517/ 13543784.11.6.787)

8 Falhammar H \& Yarker JY. Pathological gambling and hypersexuality in cabergoline-treated prolactinoma. Medical Journal of Australia 200919097.

9 Davie M. Pathological gambling associated with cabergoline therapy in a patient with a pituitary prolactinoma. Journal of Neuropsychiatry and Clinical Neurosciences 200719 473-474. (doi:10.1176/appi.neuropsych.19.4.473)

10 Gahr M, Connemann BJ \& Schonfeldt-Lecuona CJ. Pathological gambling induced by dopamine agonists. Fortschritte der Neurologie Psychiatrie 201179 470-474. (doi:10.1055/s-0031-1281580)

11 Martinkova J, Trejbalova L, Sasikova M, Benetin J \& Valkovic P. Impulse control disorders associated with dopaminergic medication in patients with pituitary adenomas. Clinical Neuropharmacology 201134 179-181. (doi:10.1097/WNF.0b013e3182281b2f)

12 Voon V, Fernagut PO, Wickens J, Baunez C, Rodriguez M, Pavon N, Juncos JL, Obeso JA \& Bezard E. Chronic dopaminergic stimulation in Parkinson's disease: from dyskinesias to impulse control disorders. Lancet Neurology 20098 1140-1149. (doi:10.1016/ S1474-4422(09)70287-X)

13 Voon V, Hassan K, Zurowski M, Duff-Canning S, de Souza M, Fox S, Lang AE \& Miyasaki J. Prospective prevalence of pathologic gambling and medication association in Parkinson disease. Neurology 200666 1750-1752. (doi:10.1212/01.wnl. $0000218206.20920 .4 \mathrm{~d})$

14 Voon V, Thomsen T, Miyasaki JM, de Souza M, Shafro A, Fox SH, Duff-Canning S, Lang AE \& Zurowski M. Factors associated with dopaminergic drug-related pathological gambling in Parkinson disease. Archives of Neurology 200764 212-216. (doi:10.1001/ archneur.64.2.212)

15 Bostwick JM, Hecksel KA, Stevens SR, Bower JH \& Ahlskog JE. Frequency of new-onset pathologic compulsive gambling or hypersexuality after drug treatment of idiopathic Parkinson disease. Mayo Clinic Proceedings 200984 310-316.

16 Weintraub D, Koester J, Potenza MN, Siderowf AD, Stacy M, Voon V, Whetteckey J, Wunderlich GR \& Lang AE. Impulse control disorders in Parkinson disease: a cross-sectional study of 3090 patients. Archives of Neurology 201067 589-595. (doi:10.1001/ archneurol.2010.65)

17 Ondo WG \& Lai D. Predictors of impulsivity and reward seeking behavior with dopamine agonists. Parkinsonism and Related Disorders 200814 28-32. (doi:10.1016/j.parkreldis.2007.05. 006)

18 Dang D, Cunnington D \& Swieca J. The emergence of devastating impulse control disorders during dopamine agonist therapy of the restless legs syndrome. Clinical Neuropharmacology 201134 $66-70$. 
19 Romigi A, Stanzione P, Marciani MG, Izzi F, Placidi F, Cervellino A, Giacomini P, Brusa L, Grossi K \& Pierantozzi M. Effect of cabergoline added to levodopa treatment on sleep-wake cycle in idiopathic Parkinson's disease: an open label 24-hour polysomnographic study. Journal of Neural Transmission 2006113 1909-1913. (doi:10.1007/s00702-006-0490-x)

20 Hogl B, Rothdach A, Wetter TC \& Trenkwalder C. The effect of cabergoline on sleep, periodic leg movements in sleep, and early morning motor function in patients with Parkinson's disease. Neuropsychopharmacology 200328 1866-1870. (doi:10.1038/sj. npp.1300250)

21 Placidi F, Izzi F, Romigi A, Stanzione P, Marciani MG, Brusa L, Sperli F, Galati S, Pasqualetti P \& Pierantozzi M. Sleep-wake cycle and effects of cabergoline monotherapy in de novo Parkinson's disease patients. An ambulatory polysomnographic study. Journal of Neurology 2008255 1032-1037. (doi:10.1007/ s00415-008-0836-4)

22 Athanasoulia AP, Ising M, Pfister H, Mantzoros CS, Stalla GK \& Sievers C. Distinct dopaminergic personality patterns in patients with prolactinomas: a comparison with nonfunctioning pituitary adenoma patients and age- and gender-matched controls. Neuroendocrinology 2012 In press.

23 Marzolini C, Paus E, Buclin T \& Kim RB. Polymorphisms in human MDR1 (P-glycoprotein): recent advances and clinical relevance. Clinical Pharmacology and Therapeutics 200475 13-33. (doi:10.1016/j.clpt.2003.09.012)

24 Uhr M, Tontsch A, Namendorf C, Ripke S, Lucae S, Ising M, Dose T, Ebinger M, Rosenhagen M, Kohli M, Kloiber S, Salyakina D, Bettecken T, Specht M, Putz B, Binder EB, Muller-Myhsok B \& Holsboer F. Polymorphisms in the drug transporter gene ABCB1 predict antidepressant treatment response in depression. Neuron 200857 203-209. (doi:10.1016/j.neuron.2007.11.017)

25 Porcelli S, Drago A, Fabbri C, Gibiino S, Calati R \& Serretti A. Pharmacogenetics of antidepressant response. Journal of Psychiatry and Neuroscience 201136 87-113.

26 Kato M, Fukuda T, Serretti A, Wakeno M, Okugawa G, Ikenaga Y, Hosoi Y, Takekita Y, Mandelli L, Azuma J \& Kinoshita T. ABCB1 (MDR1) gene polymorphisms are associated with the clinica response to paroxetine in patients with major depressive disorder. Progress in Neuro-Psychopharmacology E Biological Psychiatry 2008 32 398-404. (doi:10.1016/j.pnpbp.2007.09.003)

27 Sievers C, Ising M, Pfister H, Dimopoulou C, Schneider HJ, Roemmler J, Schopohl J \& Stalla GK. Personality in patients with pituitary adenomas is characterized by increased anxiety-related traits: comparison of 70 acromegalic patients with patients with non-functioning pituitary adenomas and age- and gendermatched controls. European Journal of Endocrinology 2009160 367-373. (doi:10.1530/EJE-08-0896)

28 Westfall PH \& Young SS. Resampling-based Multiple Testing: Examples and Methods for P-value Adjustment New York: Wiley, 1993.

29 Schneider HJ, Aimaretti G, Kreitschmann-Andermahr I, Stalla GK \& Ghigo E. Hypopituitarism. Lancet 2007369 1461-1470. (doi:10.1016/SO140-6736(07)60673-4)

30 Mihaljevic Peles A, Bozina N, Sagud M, Rojnic Kuzman M \& Lovric M. MDR1 gene polymorphism: therapeutic response to paroxetine among patients with major depression. Progress in Neuro-Psychopharmacology \& Biological Psychiatry 200832 1439-1444. (doi:10.1016/j.pnpbp.2008.03.018)

31 Peters EJ, Slager SL, Kraft JB, Jenkins GD, Reinalda MS, McGrath PJ \& Hamilton SP. Pharmacokinetic genes do not influence response or tolerance to citalopram in the STAR*D sample. PLoS ONE 2008 3 e1872. (doi:10.1371/journal.pone.0001872)

32 Laika B, Leucht S \& Steimer W. ABCB1 (P-glycoprotein/MDR1) gene G2677T/a sequence variation (polymorphism): lack of association with side effects and therapeutic response in depressed inpatients treated with amitriptyline. Clinical Chemistry $2006 \mathbf{5 2}$ 893-895. (doi:10.1373/clinchem.2006.066605)

33 Hoffmeyer S, Burk O, von Richter O, Arnold HP, Brockmoller J, Johne A, Cascorbi I, Gerloff T, Roots I, Eichelbaum M \& Brinkmann U. Functional polymorphisms of the human multidrug-resistance gene: multiple sequence variations and correlation of one allele with P-glycoprotein expression and activity in vivo. PNAS $2000 \quad 973473-3478$. (doi:10.1073/pnas. 050585397)

34 Nikisch G, Eap CB \& Baumann P. Citalopram enantiomers in plasma and cerebrospinal fluid of $\mathrm{ABCB} 1$ genotyped depressive patients and clinical response: a pilot study. Pharmacological Research 200858 344-347. (doi:10.1016/j.phrs.2008.09.010)

35 Devault A \& Gros P. Two members of the mouse mdr gene family confer multidrug resistance with overlapping but distinct drug specificities. Molecular and Cellular Biology 199010 1652-1663.

Received 7 March 2012

Revised version received 29 May 2012

Accepted 6 June 2012 